\title{
O ESTADO DEMOCRÁTICO DE DIREITO PELA TEORIA DOS FREIOS E CONTRAPESOS COMO ALICERCE DA SOBERANIA POPULAR
}

\author{
THE DEMOCRATIC RULE OF LAW BY CHECKS AND BALANCES SYSTEM AS \\ POPULAR SOVEREIGNTY BASIS
}

\author{
Ursula Eustórgio Oliveira de Azevedo ${ }^{1}$
}

RESUMO: O estudo apresentado tem como o objetivo reconhecer a enorme importância das estruturas democráticas para a manutenção do Estado democrático de direito. As estruturas democráticas sólidas são o pilar para a manutenção do Estado de Direito. A leitura pela ótica da Teoria dos freios e contrapesos para sustentação da soberania popular reconhece a separação vital dos poderes. $\mathrm{O}$ método utilizado foi de abordagem dedutiva embasado em procedimento bibliográfico, voltado para a pesquisa exploratória e documental com base nos princípios de sustentação de normas jurídicas. A relevância e originalidade da discussão jurídica se faz imperativa pela sociedade atual levando em consideração à ocorrência de atos antidemocráticos no Brasil atual. Há urgência na conscientização da população brasileira em relação à sua responsabilidade cidadã e importante proteção a soberania popular conforme aplicação das normas referentes na Constituição Federal de 1988 como contribuição teórica e metodológica.

Palavras-chave: Estado Democrático de Direito. Teoria de pesos e contrapesos. Soberania popular. Conscientização do poder popular.

ABSTRACT: The study presented aims to recognize the enormous importance of democratic structures for the maintenance of the democratic rule of law. Solid democratic structures are the pillar for maintaining the rule of law. The reading from the perspective of the checks and balances system for sustaining popular sovereignty recognizes the vital separation of powers. The method used was a deductive approach based on bibliographic procedure, aimed at exploratory and documental research based on the principles of support of legal norms. The relevance and originality of the legal discussion is imperative for today's society, taking into account the occurrence of anti-democratic acts in today's Brazil. There is an urgent need to raise the awareness of the Brazilian population in relation to their citizenship responsibility and important protection of popular sovereignty, in accordance with the norms referring to the Federal Constitution of 1988 as a theoretical and methodological contribution.

Keywords: Democratic rule of law. Checks and balances system. Popular sovereignty. Awareness of popular power.

\footnotetext{
1 Professora de Direito Administrativo, Direito Internacional e Direitos Humanos, Direito Constitucional, Direito Ambiental. Especialização em Direito Processual Civil pela Universidade Cândido Mendes - UCAM - RJ. Especialização em Advocacia Trabalhista e Previdenciária pela Universidade Cândido Mendes - UCAM - RJ. Especialização em Direito Público pela Faculdade Legale- SP. Especialização em Advocacia Extrajudicial pela Faculdade Legale-SP. Especialização em Direito Constitucional Aplicado pela Faculdade Legale- SP. Especialização em Direito Internacional e Direitos Humanos pela Pontifícia Universidade Católica de Minas Gerais/ PUC-MG (Cursando). Advogada. Graduação em Direito pela Universidade Estácio de Sá - UNESA - RJ. E-mail: ursulalink@gmail.com
} 


\section{CONSIDERAÇÕES INICIAIS}

A Constituição Federativa do Brasil de 1988, foi um marco histórico para o Estado Democrático de Direito, onde o Brasil sobreviveu a imposição da ditadura militar violenta durante décadas, com delimitação da maioria de todos os direitos possíveis superando um ciclo de atrasos na consolidação de todos os direitos, principalmente os democráticos.

Com a instauração da democracia, depois de um processo de anos de escuridão fundamental de direitos, a Constituição Federativa de 1988 assegurou ao país mais de três décadas de estabilidade institucional. A importância da edificação da democracia, também assegurada pelo artigo $\mathrm{I}^{\mathrm{o}} \mathrm{da} \mathrm{CRFB} / 88$, onde em seu parágrafo único celebra a soberania popular na construção da sua democracia ao referir-se que "Todo o poder emana do povo, que o exerce por meio de representantes eleitos ou diretamente, nos termos desta Constituição". Destarte, o poder emanado surge como vontade universal e proporciona a alternância saudável de poder, através e diretamente da escolha popular, glorificando dessa maneira a democracia brasileira.

Os três poderes do Estado como executivo, legislativo e judiciário, devem assegurar o desempenho harmônico de suas atividades para reverenciar a primazia dos princípios de equilíbrio democrático, para tanto a Teoria de Pesos e Contrapesos originada nos ideais do atilamento da caminhada republicana, laureadas pela precedência da força da soberania popular.

\section{ESTADO DEMOCRÁTICO DE DIREITO}

A Democracia Ateniense foi um regime político criado e adotado em Atenas, no período da Grécia Antiga. Ela foi essencial para a organização política das cidades-estados grega, sendo o primeiro governo democrático da história. O termo "Democracia" é formado pelo radical grego "demo" (povo) e de "kratia" (poder), que significa "poder do povo”.

Anterior a implementação da Democracia em Atenas, a cidade-estado era controlada por uma elite aristocrática oligárquica denominada de "eupátridas" ou "bemnascidos”, os quais detinham o poder político e econômico na polis grega. Entretanto, com o surgimento de outras classes sociais como comerciantes, pequenos proprietários de terra, artesãos, camponeses, as quais pretendiam participar da vida política, a aristocracia resolve 
rever a organização política das cidades-estados, o que mais tarde resultou na implementação da "Democracia".

De tal maneira, por volta de 5ı a.C. a democracia surge em Atenas através da vitória do político aristocrata grego Clístenes. Considerado o "Pai da Democracia", ele liderou uma revolta popular contra o último tirano grego, Hípias, que governou entre 527 a.C. e 510 a.C.. Após esse evento, Atenas foi dividida em dez unidades denominadas chamadas "demos", que era o elemento principal dessa reforma e, por esse motivo, o novo regime passou a se chamar "demokratia”. Atenas possuía uma democracia direta, onde todos os cidadãos atenienses participavam diretamente das questões políticas da polis.

A democracia ateniense foi um modelo político que foi copiado por várias sociedades antigas, e que influencia até hoje o conceito de democracia no mundo.

A democracia atual é um modelo mais avançado e moderno da democracia ateniense, em que todos os cidadãos, maiores de 16 ou I8 anos, inclusive mulheres, podem votar e ocupar a cargos públicos, sem que seja excludente e limitada.

Além disso, na democracia ateniense, os cidadãos tinham uma participação direta na aprovação das leis e nos órgãos políticos da polis, enquanto na democracia atual, democracia representativa, os cidadãos elegem um representante.

Ao longo da história, diferentes articulistas escritores arrazoaram sobre a corrente Tripartite que constitui a separação do governo em três, tendo Aristóteles o desbravador originário em sua obra "A Política” que considera a existência de três órgãos separados a quem incumbiam as decisões de Estado. Eram eles o Poder Deliberativo, o Poder Executivo e o Poder Judiciário.

John Locke foi um filósofo inglês conhecido como o "pai do liberalismo", sendo considerado o principal representante do empirismo britânico e um dos principais teóricos do contrato social, escreve em sua obra "Segundo Tratado Sobre o Governo Civil", a defesa de um Poder Legislativo superior aos demais, o Executivo com a finalidade de aplicar as leis, e o Federativo, mesmo tendo legitimidade, não poderia desvincular-se do Executivo.

Charles-Louis de Secondat, barão de La Brède e de Montesquieu, conhecido como Montesquieu, foi um político, filósofo e escritor francês que criou a tripartição e as devidas atribuições do exemplo acolhido atualmente, sendo o Poder Legislativo responsável pelas leis, seja temporária para determinada época ou duradoura com o poder de aperfeiçoar ou 
revogam as já existentes. Já o Executivo seria o poder que se ocupa o Príncipe ou Magistrado da paz e da guerra nas relações internacionais com o estabelecimento da segurança e prevenção de invasões. Para o poder Judiciário, poder esse que oferece ao Príncipe ou Magistrado a competência de punir os crimes ou julgar os litígios da ordem civil. Montesquieu, de acordo com esse pensamento, confere a forma tripartite como modelo delimitando o poder em mãos diferentes, nas tarefas de legislar, administrar e julgar, observando que consequentemente e historicamente a concentração de poder demonstrou o abuso advindo desse.

Quando o Estado figura como detentor absoluto da força e do poder sobre o povo que habita seu território, calculava-se para que os governados, teoricamente, tivessem uma garantia contra arbitrariedades, a necessidade de ordenação do exercício desse poder supremo e, para tanto, surgem as leis que obrigam à submissão aos seus comandos, tanto o povo em geral, como os próprios governantes que as criam e as executam. Tem-se, assim, a formação do Estado de Direito, que traz como característica básica o primado da legalidade, isto é, o governo das leis, que se contrapõe ao governo dos homens.

O Estado Democrático de Direito apresenta como qualidades básicas a submissão às leis, a divisão de funções estatais, bem como o enunciado e a garantia dos direitos individuais, mas busca, sobretudo, a justiça social e a autêntica participação democrática do povo em seu processo político, respeitando sempre as diferenças estruturais existentes entre as pessoas, tais como etnias, diferentes crenças e culturas, a diversificação da situação social. O Estado Democrático de Direito vem sendo um pilar não apenas na obediência em seu âmbito de atuação à legalidade, mas também e principalmente, na existência da necessidade de legitimidade de suas decisões, legitimidade esta que só é alcançada quando respaldada pela vontade do povo, o que se dá mediante a participação na formação da vontade estatal, individualmente, ou por meio de organizações sociais ou profissionais. Isto porque é a participação que proporciona à população a oportunidade de manifestar livremente, sem restrições, sua própria vontade.

No Estado Democrático de Direito parte-se da premissa na qual os destinatários das normas reconheçam-se como seus autores. Trata-se o Estado de uma instância jurídica de produção e aplicação do direito; o Estado é instrumento jurídico de atuação das funções públicas institucionalizadas e criadas constitucionalmente pelo povo. ${ }^{2}$

${ }^{2}$ LEAL. Teoria processual da decisão jurídica. 2002. p. I68 


\section{TEORIA DE FREIOS E CONTRAPESOS DIANTE DA DOUTRINA CONSTITUCIONAL NO BRASIL}

O pensador francês Charles-Louis de Secondat, Baron de La Brède et de Montesquieu, na sua obra "O Espírito das leis”, baseada nas obras de Aristóteles, elucidou sobre a Teoria da Separação dos Poderes conhecida, como Sistema de Freios e Contrapesos.

Dentre os filósofos que tentava compatibilizar ciência e filosofia, John Locke, tentava valorizar a experiência como fonte de conhecimento. O pensamento empírico de Locke influenciou as bases das democracias liberais entusiasmando iluministas franceses em suas obras, as principais ideias que representaram, de forma emblemática, a Revolução Francesa. A Teoria da Separação dos Poderes de Montesquieu foi inspirada em Locke que, também, influenciou significativamente os pensadores norte-americanos na elaboração da Declaração de sua independência, em 1776.

Para Locke, os homens nasciam livres e com direitos iguais. Locke sustentava que o estado da sociedade e, consequentemente, o poder político, nascem de um pacto entre os homens. Antes desse acordo os homens viveriam em estado natural, tal como pensava Hobbes, segundo o qual todos os homens teriam o destino de preservar a paz e a humanidade e evitar ferir os direitos dos outros, deveres que Locke considerava próprios do estado natural.

O pacto social primordial seria apenas um acordo entre indivíduos reunidos com a finalidade de empregar sua força coletiva na execução das leis naturais renunciando a executá-las pelas mãos de cada um. O objetivo desse pacto seria a preservação da vida, da liberdade e da propriedade. Locke acreditava que os homens, ao se organizarem em sociedade, cediam ao Estado parte de sua igualdade e liberdade, a fim de manter a segurança. $\mathrm{Na}$ sociedade política, as leis aprovadas por mútuo consentimento de seus membros seriam aplicadas por juízes imparciais e manteriam a harmonia geral entre os homens. O soberano seria, assim, o agente executor da soberania do povo.

No pensamento de Locke, o mesmo homem que confiava o poder ao soberano era capaz de dizer quando se abusa desse poder. Os pleitos deveriam ser resolvidos por juízes neutros e honestos, de acordo com as leis. E, tudo isto, não deveria estar dirigido a outro fim que não fosse o de conseguir a paz, a segurança e o bem do povo. Essas ideias estruturaram a base do moderno princípio da Separação dos poderes, que começou, pois, 
por transportar uma ideia de moderação e de compromisso. A ideia da divisão de poderes seria para evitar a concentração absoluta do poder nas mãos do soberano, comum no Estado absoluto, que precede as revoluções burguesas, buscando evitar o abuso de poder e garantir a liberdade dos indivíduos. Assim, Montesquieu pensou a separação de poderes como um mecanismo para evitar esta concentração de poderes e estabelecer uma espécie de controle mútuo.

Montesquieu acreditava que o Sistema de freios e contrapesos, onde cada poder é autônomo e deveria exercer determinada função, porém, este poder deveria ser controlado pelos outros poderes. Verifica-se, ainda, que mediante esse Sistema, um Poder do Estado está apto a conter os abusos do outro de forma que se equilibrem. O contrapeso está no fato que todos os poderes possuem funções distintas, são harmônicos e independentes entre si.

A aplicação do Sistema de freios e contrapesos significa a contenção dos abusos dos outros poderes para manter certo equilíbrio. Para essa teoria os Estados livres, eram os Estados moderados, onde não se abusasse do poder, muito embora a história comprova que todo homem que tem poder é tentado a abusar dele, indo até os seus limites. Para que o abuso de poder não ocorra, é necessário que o poder freie o poder.

O Sistema de Freios e Contrapesos consiste no controle do poder pelo próprio poder, sendo que cada Poder teria autonomia para exercer sua função, mas seria controlado pelos outros poderes. Isso serviria para evitar qualquer abuso no exercício do poder por algum dos Poderes (Executivo, Legislativo e Judiciário). Desta forma, embora cada poder seja independente e autônomo, deve trabalhar em harmonia com os demais Poderes.

A Teoria da Separação dos Poderes surgiu na época da formação do Estado Liberal baseado na livre iniciativa e na menor interferência do Estado nas liberdades individuais. Essa tripartição clássica dos poderes se dá até hoje, na maioria dos Estados, e está consolidada pelo artigo i6 da Declaração Francesa dos Direitos do Homem e do Cidadão (1789) e prevista no artigo $2^{-}$da nossa Constituição Federal brasileira, sendo divididas e especificadas as funções de cada poder.

O poder é uma forma de controle social capaz de direcionar a conduta de um determinado grupo de pessoas. Contudo, o exercício do poder tende, a ultrapassar e, até mesmo, abusar dos limites estabelecidos pela lei. Logo, é fundamental a constante alternância dos dirigentes nos poderes Legislativo e Executivo, nos regimes democráticos. 
Muito bem constatado na CRFB/88 descrita no "Art. 2웅 São Poderes da União, independentes e harmônicos entre si, o Legislativo, o Executivo e o Judiciário."3

O princípio basilar dos poderes harmônicos e independentes acabou por dar origem ao conhecido Sistema de freios e contrapesos, onde os atos gerais, praticados exclusivamente pelo Poder Legislativo, consistentes na emissão de regras gerais e abstratas, limita o Poder Executivo, que só pode agir mediantes atos especiais, decorrentes da norma geral. Para impedir o abuso de qualquer dos poderes de seus limites e competências, dá-se a ação do controle da constitucionalidade das leis, da decisão dos conflitos intersubjetivos e da função garantidora dos direitos fundamentais e do Estado Democrático de Direito, pelo Poder Judiciário.

A teoria de freios e contrapesos vem por garantir a plena liberdade política dos indivíduos e dos direitos das minorias. Edifica a formação do Estado de Direito, na medida em que previne o abuso governamental submetendo governantes e governados as regras e aos procedimentos legais, onde ninguém é obrigado a fazer ou deixar de fazer alguma coisa senão em virtude de prévia determinação legal.

A Separação de poderes é pressuposto do constitucionalismo, prevista na

Declaração dos Direitos do Homem e do Cidadão, de 1789. A separação de poderes carrega de forma construtora a mais difusa polissemia de toda a dogmática do direito público, posto que aponta simultaneamente para os princípios de desagregação e de composição, num sistema de freios e contrapesos.

O Brasil é uma República Federativa e tem como princípio fundamental o Princípio da separação dos seus poderes Legislativo, Executivo e Judiciário. No preâmbulo da Constituição Federal brasileira de 1988 apresenta o Brasil, pela Assembleia Nacional Constituinte, como um Estado Democrático, destinado a assegurar o exercício dos direitos sociais e individuais, a liberdade, a segurança, o bem-estar, o desenvolvimento, a igualdade e a justiça como valores supremos de uma sociedade fraterna, pluralista e sem preconceitos, fundada na harmonia social e comprometida, na ordem interna e internacional, com a solução pacífica das controvérsias. Determinante na Constituição

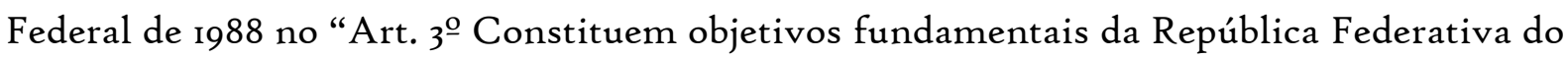
Brasil: I - construir uma sociedade livre, justa e solidária; II - garantir o desenvolvimento nacional; III - erradicar a pobreza e a marginalização e reduzir as desigualdades sociais e

\footnotetext{
3 http://www.planalto.gov.br/ccivil_03/constituicao/constituicaocompilado.htm ( acesso em 28/o9/202I)
} 
regionais; IV - promover o bem de todos, sem preconceitos de origem, raça, sexo, cor, idade e quaisquer outras formas de discriminação."

A separação dos poderes é uma garantia admirável que foi alçada à dimensão constitucional, fruto do desejo e a intenção constituinte de estabelecer funções diferenciadas, conjugando princípios por vezes aparentemente contrapostos, com o objetivo de proteger e garantir o exercício dos direitos individuais e coletivos.

\section{IMPORTÂNCIA DA SOBERANIA POPULAR}

Conforme disposto no artigo n⿳ $\mathrm{n} 4$ da Carta Magna Brasileira de $1988^{4}$, "A soberania popular será exercida pelo sufrágio universal e pelo voto direto e secreto, com valor igual para todos, e, nos termos da lei, mediante: I - plebiscito; II - referendo; III iniciativa popular."

A palavra soberania tem em seu sentido a qualidade de quem é soberano de autoridade suprema e popular em seu entendimento mais profundo e importante da nossa democracia é aquilo que pertence ou se relaciona ao povo, ou o próprio povo.

A soberania política, pertence ao povo, a mais ninguém. O povo é quem tem o poder de assentar a soberania política. Esse povo, o povo brasileiro, onde todos são iguais perante a lei, sem distinções de qualquer natureza, no gozo das garantias do direito inviolável à vida, à liberdade, à igualdade, à segurança e à propriedade, conforme disposto na Constituição República Federativa do Brasil de 1988 em seu artigo 5ํo.

A sociedade e a história construída através de dispositivos legais mirados em nossa Constituição carecem encontrar a fraternidade, o pluralismo, o respeito à diversidade, onde qualquer violação desses atributos enseja em limitações ao direito de votar e ser votado.

A importância da escolha popular, reverbera a voz da população, dos desejos, da ótica do desenvolvimento cognitivo do povo. No caminho dessa evolução, a experiência eleitoral, a manifestação de vontades, a grandeza do crescimento que só pode evoluir, mesmo dentre a consagração entre escolhas e arrependimentos, é dessa forma genuína que o Brasil respeita sua importante soberania popular. Quem, de fato, manifesta o poder sempre é, e será o povo. Os gestores que são eleitos, têm pelo sortilégio da democracia, um

\footnotetext{
${ }^{4}$ http://www.planalto.gov.br/ccivil_03/constituicao/constituicaocompilado.htm (acesso em 20/o9/202I)
} 
poder temporário, escolhido por um coletivo, constando na leal alternância de manifestações do poder popular.

A força construtiva da soberania popular é a maior instituição do Estado Democrático de Direito. A conscientização do poder que o povo brasileiro possui para a alternância de governos deve ser provocada, aquecida por debates sobre a sociedade atual e as necessidades de mudanças para o desenvolvimento econômico e social. O Brasil está evoluindo no processo de construção do regime democrático, com o verdadeiro sentido da mais nobre soberania política popular, onde todas as escolhas são diversificadas, preservando assim o caminho apontado pelo Preâmbulo da Constituição.

\section{CRIMES CONTRA O ESTADO DEMOCRÁTICO DE DIREITO}

Qualquer ataque ou tentativa de dissolver ou quebrar a edificação do Estado Democrático de Direito no país é caracteristicamente um crime contra a Democracia. As normas constitucionais definem o sistema republicano, democrático e representativo no qual o voto é o meio pelo qual se ascende ao cargo político-eleitoral, não se admitindo a tomada violenta do poder.

$\mathrm{Na}$ nova Lei instituída, $\mathrm{n}^{\mathrm{o}}$ 14.197, de $\mathrm{I}^{\mathrm{o}}$ de setembro de $202 \mathrm{I}^{5}$, lei que acrescenta aos crimes contra o Estado Democrático de Direito, e revoga a Lei no 7.17o, de 14 de dezembro de 1983, Lei de Segurança Nacional e o art. 39 do Decreto-Lei no 3.688, de 3 de outubro de 194I sobre Lei das Contravenções Penais.

Além de revogar a Lei de Segurança Nacional essa nova legislação busca regulamentar dispositivos da Constituição definindo que as ações de grupos armados, militares ou civis, contra a ordem constitucional e o Estado democrático são imprescritíveis e inafiançáveis. Toda democracia necessita de meios legais e jurídicos que propiciem sua autodefesa. Ainda que saibamos que a defesa da democracia deve ser realizada pela sociedade organizada e pelas instituições, mediante movimentos que revelem a consciência democrática da nação e do povo, esses movimentos necessitam de ferramentas jurídicas que sirvam para conferir eficiência a seu propósito democrático.

A nova legislação esclareceu relacionando e tipificando todos os crimes contra o Estado Democrático de Direito, crimes esses tais como contra a soberania nacional: atentado à soberania, atentado à integridade nacional; espionagem. Os crimes contra as

\footnotetext{
${ }^{5}$ http://www.planalto.gov.br/ccivil_03/_ato2019-2022/2021/lei/L14197.htm ( acesso em 25/09/2021)
} 
instituições democráticas: abolição violenta do Estado democrático de direito; e golpe de Estado. Os crimes contra o funcionamento das instituições democráticas no processo eleitoral: interrupção do processo eleitoral e violência política. Os crimes contra o funcionamento dos serviços essenciais: sabotagem.

A lei no 14.197 , de $\mathrm{I}^{\mathrm{o}}$ de setembro de 2021 informa ainda que não constitui crime a manifestação crítica aos Poderes constitucionais nem a atividade jornalística ou a reivindicação de direitos e garantias constitucionais por meio de passeatas, de reuniões, de greves, de aglomerações ou de qualquer outra forma de manifestação política com propósitos sociais.

\section{CONCLUSÃO}

A essência da democracia é o fato de o poder residir no povo; repousar na vontade popular no que tange à fonte do exercício do poder; o conceito de democracia fundamentase na existência de um vínculo entre o povo e o poder; como este recebe qualificações na conformidade de seu objeto e modo de atuação; a democratização do poder é fenômeno histórico, conforme o advento de qualificações da democracia para apresentar a democracia política, a social e a econômica.

A teoria da tripartição de poderes apresentada pela teoria de freios e contrapesos, assinalando que o poder do Estado é sempre uno e indivisível. Apresentando na realidade, a distribuição de certas funções a diferentes órgãos do Estado, ou seja, 'a divisão de funções estatais. É vital a importância da teoria de Montesquieu para a atualidade, de modo que, decorridos mais de duzentos anos, suas ideologias demonstram-se ainda atuais, modernas e atrativas, compondo diversos textos constitucionais em todos os continentes, compreendendo a Constituição da República Federativa do Brasil de 1988.

Vale ressaltar a frase de Franklin D. Roosevelt: “A democracia não pode ter sucesso a menos que aqueles que expressam sua escolha estão preparados para escolher sabiamente. A verdadeira salvaguarda da democracia, portanto, é a educação."

A consciência da soberania popular é o pilar edificado pelo Estado Democrático de Direito, equilibrado e estruturado pela teoria sistemática de freios e contrapesos para regular a harmonia entre os poderes bem como a solidificação essencial da Democracia. 


\section{REFERÊNCIAS}

ARISTÓTELES. A Política. São Paulo: Martins Fontes, 2001.

ALARCÓN, Pietro de Jesus Lora. A democracia semidireta na Constituição de 1988. Revista de Direito Constitucional e Internacional, no 33, 2000.

BASTOS, Celso Ribeiro. Curso de Direito Constitucional. I2.ed. São Paulo: Saraiva, I99o.

BOBBIO, Norberto. Estado, Governo e Sociedade- Para uma teoria geral da política. 2.ed. São Paulo: Paz e Terra, 1988.

CRETELLA JR., José. Comentários à Constituição Brasileira de 1988. 2.ed. Rio de Janeiro: Forense Universitária, 1990. v.I.

DALlARI, Dalmo de Abreu. Elementos de Teoria Geral do Estado. i4.ed. São Paulo: Saraiva,1989.

DIAS, Luiz Cláudio Portinho. A democracia participativa brasileira. Revista de Direito Constitucional e Internacional, no 37 , 200I.

FERREIRA FILHO, Manoel Gonçalves. Curso de Direito Constitucional. I8.ed. São Paulo: Saraiva, I990.

FERREIRA, Pinto. Comentários à Constituição Brasileira. São Paulo: Saraiva, 1989. V.I.

LEAL, Rosemiro Pereira. Teoria Processual da Decisão Jurídica. São Paulo: Landy Editora e Distribuidora Ltda., 2002.

LENZA, Pedro. Direito constitucional esquematizado. 23ํㅡ. ed. São Paulo: Saraiva, 2020. 
LOCKE, John. Segundo Tratado sobre o Governo Civil. Trad. Alex Marins, São Paulo. Martin Claret: 2003.

MATSUMOTO, Katsutoshi. O Estado Democrático de Direito. Revista de Direito Constitucional e Internacional, n.33, 2000.

MONTESQUIEU, Charles de Secondat. O Espírito das Leis. Introdução, trad. e notas de Pedro Vieira Mota. $7^{\text {a }}$ ed. São Paulo. Saraiva: 2000.

SILVA, José Afonso. Curso de Direito Constitucional Positivo. io ed. São Paulo: Malheiros Editores, 1995 